\title{
A Presença do jogo na infância de octogenários e nonagenários
}

\author{
The presence of the play in \\ octogenarians childhood and nonagenarians
}

\author{
Kleber Tuxen CARNEIRO' \\ Eliasaf Rodrigues de ASSIS² \\ Maurício BRONZATTO ${ }^{3}$ \\ Ricardo Leite de CAMARGO 4
}

\begin{abstract}
Resumo
Este artigo apresenta os resultados de um estudo de doutoramento cujo objetivo foi conhecer diferentes manifestaçóes da cultura lúdica na infância de octogenários e nonagenários, vivida nas décadas de 20 e 30 . Considerou-se que as distintas configuraçóes assumidas pela infância produzem diferentes cenários que podem influenciar a forma e o conteúdo da constituição da cultura lúdica. Com base no método História Oral, que resgatou a infância rememorada dos 32 guardióes da memória, procurou-se escavar o substrato do lúdico daquele momento histórico. Discutiu-se, ainda, a importância de preservar a memória lúdica, afetada por vários fatores, podendo sofrer perdas, desapegos e esquecimentos.
\end{abstract}

Palavras-chave: Jogo. Memória. Cultura Lúdica.
Abstract

This article show off the results of a doctoral study whose objective was to better understand the different manifestations of ludic culture in childhood the octogenarians and nonagenarians, borns in the decades of 20 and 30 . He took into account the different configurations assumed by childhood produce different scenarios that may influence the form and content of the constitution of ludic culture. Based on the method of oral history, which rescued the childhood remembered the 32 guardians of memory, tried to delve this ludic substrate that historic moment. Also it discussed the importance of preserving the ludic memory, which is directly affected by various factors, which may suffer losses, detachments and forgetfulness.

Keywords: Play. Memory. Ludic culture.

1 Doutor em Educação Escolar, no momento desenvolve Estágio de Pós-Doutoramento junto a Faculdade de Educação da Unicamp. Professor Adjunto na Universidade Federal de Lavras/MG e membro/pesquisador do GEFORDEF (Grupo de Estudo/Pesquisa em Formação Docente sobre Educação Física). Endereço: Universidade Federal de Lavras Campus Universitário - Caixa Postal 3037 Lavras/MG - CEP 37200-000 - Fone: (35)38295270 - E-mail:<kleber2910@gmail.com>.

2 Doutor em Educação Escolar, pela Unesp/Fclar. Participa como pesquisador colaborador no GEFORDEF (Grupo de Estudo/Pesquisa em Formação Docente sobre Educação Física). E-mail:<eliasafassis@hotmail.com>.

3 Doutor em Educação Escolar. Professor do Instituto Federal de Educação, Ciência e Tecnologia de São Paulo, Campus Salto. Endereço: Rua Rio Branco, 1780 - Vila Teixeira - Salto/SP - CEP 13320-271 Fone: (11)4602-9191 - E-mail:<maub1970@ig.com.br>.

4 Professor Livre Docente em Educação. Docente no Departamento de Economia, Administração e Sociologia na ESALQ/USP. Endereço: Av. Pádua Dias, 11, - Vila Independência - Piracicaba/SP - CEP 13418900 - Caixa-postal: 9 Fone: (19)34294376 - E-mail:<ricardocamargo@usp.br>.

R. Educ. Públ.

Cuiabá

v. 27

n. 66

p. $815-838$

set./dez. 2018 


\section{Introdução}

Foi o interesse em recuperar fragmentos de uma infância adormecida que engendrou esta pesquisa. Esse interesse teve um alvo específico. Náo se pretendeu encontrar qualquer elemento, dentre tantos que compóem a construção social da infância, mas um em especial: o jogo, personificado no ato de brincar, para o qual, segundo Bastide (apud FERNANDES, 1979), os adultos, vez ou outra, olham com alguma desconfiança.

Propusemos esta investigação com o objetivo principal de conhecer as diferentes manifestações da cultura lúdica (jogo) na infância de octogenários e nonagenários. Procuramos, portanto, resgatar o conteúdo lúdico dentro de um período histórico bem peculiar, as décadas de 20 e 30 . Para isso, procuramos dar $v o z$ aos 32 anciáos participantes do trabalho, a fim de que narrassem a forma e as diferentes personificaçôes da cultura lúdica (do jogo) em sua infância.

Ao optarmos por entrevistar sujeitos na faixa etária dos 80 e 90 anos, levamos em consideração a urgência de preservar um tesouro prestes a finar-se com seus possuidores, necessidade não tão premente se se tratasse de uma amostra com média de idade entre 50 e 60 anos. A legitimidade de nossa preocupaçáo logo se verificou: em menos de três anos depois da coleta de dados, 12 dos 32 entrevistados já não estavam mais vivos.

Além desse interesse central, a pesquisa objetivou também conhecer as características da cultura lúdica quanto: a) ao espaço e principais tipologias do jogo e brinquedos das décadas de 20 e 30 ; b) às particularidades historicamente construídas para a infância da época, as quais produziram diferentes cenários para as manifestações do jogo; c) às organizaçôes, ou relações sociais, engendradas pelo ambiente do jogo; e d) a um possível crepúsculo das particularidades do jogo/ folclore (tradicional) em relação a outras formas de expressão do jogo na atualidade.

Em nosso entendimento, no espaço da cultura lúdica (ou do jogo), a criança se relaciona com conteúdos culturais que ela reproduz e transforma. Também deles se apropria, atribuindo-lhes significaçóes e ressignificaçóes. Desse modo, de alguma forma, as diferentes personificaçôes do jogo constituem-se como um ingresso na cultura, uma vez que tal fenômeno é também uma construção social. É preciso esclarecer que não estamos nos referindo a qualquer forma de expressão cultural, mas a uma forma e a um conteúdo muito particulares, que existem num dado momento, dentro de um contexto histórico (BROUGÈRE, 1997).

Podemos assumir, assim, que a cultura lúdica se caracteriza como um patrimônio cultural, ou seja, conjuntos de conhecimentos e realizaçôes de uma sociedade. Esses conjuntos são acumulados ao longo da história de uma dada sociedade e conferem 
traços de singularidade em relação a outras sociedades. Portanto, ao adotarmos essa forma de conceber a cultura lúdica, reconhecemos também a importância de preservar e transmitir, de geração em geração, seu conteúdo, reconhecidamente um tesouro, às vezes escondido, que se esculpiu ao longo da história.

Desse modo, ao considerarmos o cenário atual, que apresenta uma diminuição significativa de determinados artefatos e expressóes lúdicas, entendemos ser necessário salvaguardar tais elementos, por meio da perpetuação da memória lúdica, pois essa é a alternativa que nos resta para a preservação desse patrimônio cultural e afetivo da humanidade. No entanto, reconhecendo a dinâmica do tecido que compóe as tramas lúdicas, também reconhecemos suas ressignificaçóes, ou seja, as novas configuraçóes e formatos. Ao olharmos para a história do jogo e seus múltiplos cenários, notamos o quanto o quadro contemporâneo se difere e distancia daquele engendrado em épocas passadas, o que, de algum modo, justifica esforços para se pensar caminhos (metodológicos e epistemológicos) que dialoguem com as novas expressóes de jogo (por exemplo, os eletrônico-digitais) e, concomitantemente, preservem o legado de algumas personificaçóes singulares da cultura lúdica, como o jogo/folclore (tradicional).

Cabe destacar que a realização desta pesquisa não se deveu a um impulso saudosista, pois, no espaço da cultura lúdica, a criança se relaciona com conteúdos culturais que ela reproduz e transforma, ou seja, há uma dinâmica de significaçóes e ressignificaçóes no interior da cultura lúdica própria da vida social.

Propusemos esta investigação com o objetivo de contribuir para a preservação da memória lúdica, em geral afetada por fatores como a transitoriedade grupal e as transformaçóes gerais (arquitetônicas, simbólicas, entre outras) que podem produzir perdas, desapegos e esquecimentos da memória coletiva. Atuamos, portanto, como arqueólogos a escavar as narrativas de nossos Guardióes da Memória em busca de sua cultura lúdica.

\section{Referencial teórico}

O trabalho assenta-se em três grandes bases epistemológicas. A primeira e mais extensa é composta pelos fundamentos da teoria do jogo. A complexidade que envolve a teoria do jogo pode ser facilmente percebida quando se observam as diferentes áreas, sejam das ciências humanas, sejam das ciências exatas, que se propuseram a desenvolver investigaçôes tomando-o como objeto de conhecimento: na Psicologia do desenvolvimento, temos Rosamilha (1979), 
Vygotsky (2000), Piaget (1994), Macedo (2000), Winnicott (1975), Elkonin (1998), Buytendijk (1974); nas Ciências Exatas/Matemática, Eigen e Wincker (1989), que se preocuparam em estudar as leis naturais que regulam o acaso; ou ainda os estudos dos matemáticos Neumane Morgenstern (1990) e John Nash (NASAR, 2002), esse último ganhador do Prêmio Nobel de Economia de 1994.

O jogo também está presente na Filosofia, com os estudos de Pascal (2003), Schiller (2002), Rousseau (1974), Leibniz (apud DUFLO, 1999), Gadamer (2002), Wittgenstein (1999), entre outros; igualmente na História: Ariès (1981) e o clássico Homo Ludens, de Huizinga (1999); também na Sociologia, nos estudos de Brougère (1997, 1998), Caillois (1990) e Benjamin (1984). Já na Pedagogia, tivemos importantes investigaçóes, dentre as quais destacamos os estudos de Kishimoto (2003, 2006), Château (1987), Friedmann (1996), Leif e Brunelle (1978), Miranda (2001), Duarte Jr. (1988), Lebovicie Diatkine (1988) e Maturana e Verden-Zöller (2004).

Por último, enfatizamos as importantes contribuiçôes da Educação Física para a investigação do jogo nos estudos de Paes (1992), Mello (1989), Bruhns (1989, 1993), Marcelino (1987, 1989), Freire (2001), Freire e Scaglia (2003), Scaglia (2003), Scaglia, Carneiro e Camargo (2014), Carneiro (2009, 2012, 2015, 2017), Retondar (2007), dentre outros. A extensa lista de pesquisadores da teoria do jogo e das áreas que dele se ocuparam dá mostras de sua complexidade e abrangência.

A segunda base epistemológica deste trabalho diz respeito aos constructos da memória e é subsidiada por estudiosos como: Halbwachs (1990), Bergson (1999), Bosi (1987), Connerton (1999), Santos (2002), Olick e Robbins (1998), Fentress e Wickham (1992), Lowenthal (1998), entre outros, cujo entendimento sobre memória fornece sentido ao tempo presente de um grupo ou de um indivíduo, sentido esse que deve ser continuamente construído, uma vez que a memória não é estática, pois na base da sua formação encontramse os aferentes (a negociação) entre as lembranças do sujeito ou grupo e as dos outros grupos ou sujeitos. Halbwachs (1990) destaca essa característica como a condição fundamental para que as lembranças sobrevivam: quando lembramos, mesmo que nos achemos sozinhos, tal ato implica a inserção em um meio social que o possibilita. Mais do que contexto, lembrar implica partilhar lembranças.

E, por fim, a terceira base deste estudo ocupou-se da apresentação de um esboço a respeito dos diferentes olhares e entendimentos sobre a infância e, por conseguinte, sobre a criança. Discutiu-se a imprecisão que perpassa o conceito e o quanto uma hermenêutica da infância se coloca como um desafio a quem intente compreendê-la. Os principais autores com quem 
dialogamos foram: Lira (2009), Narodowski (2001), Becchi (1998), Steinberg e Kincheloe (2001), Veiga (2004), Kuhlmann Jr. e Fernandes (2004), Ariès (1981), Postman (1999), Dornelles (2005), Bujes (2005), entre outros.

\section{Percurso metodológico}

Os procedimentos metodológicos de que nos servimos para alcançar os objetivos propostos para esta investigaçáo assentam-se sobre o fundamento das disposiçóes gerais da abordagem qualitativa, que, de acordo com Chizzotti (2003), conferem a possibilidade de observar/compreender os valores, crenças, hábitos, atitudes, representaçóes, opinióes sobre fatos e processos particulares e específicos dos indivíduos e grupos em que estão inseridos.

Para os fins de nossa investigação, elegemos o método denominado História Oral, que se reporta à narrativa para buscar o significado das vivências, experiências pessoais, familiares, profissionais, comunitárias e sociais dos indivíduos. Essa técnica torna possível aprofundar o conhecimento da realidade a partir da concepção que o pesquisado lhe atribui (MARTINELLI, 2003).

Optou-se, nesta pesquisa, pelo uso da entrevista semiestruturada. Este procedimento, comumente empregado na metodologia História Oral, possibilita a utilizaçáo de um roteiro com questóes previamente definidas e o acréscimo de novas perguntas, caso haja necessidade (BONI; QUARESMA, 2005).

Atendendo a nosso roteiro, os entrevistados responderam inicialmente a perguntas relativas a dados pessoais (idade, nome, composição familiar, religião, etc.) e, a seguir, ao histórico familiar (origem, descrição da família e dos relacionamentos familiares, descrição da escola da época, etc.).

O último bloco constituiu-se de perguntas que abordavam as especificidades da infância (como era, principais jogos/brincadeiras, o espaço do jogo/ brincadeiras na escola, intervalo, a confecção de brinquedos, a aquisição de brinquedos industrializados, etc.).

$\mathrm{Na}$ maior parte das vezes, para a realização de uma única entrevista, foram necessários vários encontros, em decorrência de algumas especificidades de nossos sujeitos (baixa resistência, interferências dos familiares, tratamento e cuidados com a manutenção da saúde, entre outros), o que desencadeou um extenso período de coleta de dados. Sendo assim, o tempo total para a realização de todas as entrevistas, registrado em nossas gravaçôes, somou vinte horas, dezessete minutos e vinte e três segundos (20:17’23”), com uma média de dezoito minutos e quarenta e oito segundos por entrevistado. 


\section{Lócus da pesquisa, participantes e materiais}

Os locais para o desenvolvimento da pesquisa corresponderam ao da moradia dos entrevistados. A dificuldade em encontrar pessoas na faixa entre 80 e 90 anos em condiçôes de integrar nossa amostra fez com que tivéssemos que procurá-las na capital paulista e em diferentes municípios do interior desse Estado. Mogi das Cruzes, Campinas, Paulínia, Sumaré, Nova Odessa, Americana, Santa Bárbara D’Oeste e Piracicaba completam a lista das cidades onde residiam nossos entrevistados.

O grupo amostral contou com 32 voluntários, com idades variando entre 80 e 90 anos, sendo 20 mulheres e 12 homens. Quanto aos critérios para definiçáo da quantidade de sujeitos a serem pesquisados, considera-se que tal decisão adveio da própria metodologia adotada. A História Oral, tomada como um método de pesquisa, defende a não exigência de quantidade, pois parte da compreensão de que os pesquisados não devem ser considerados como unidades estatísticas (ALBERTI, 2004), mas sim como pessoas de valor inestimável, as quais representam um referencial qualitativo "em função de sua relação com o tema estudado" (ALBERTI, 2004, p. 32).

Para a coleta dos dados, foram usados uma câmera fotográfica digital e, em alguns momentos, concomitantemente, um gravador digital, para que se garantisse a qualidade do registro e contássemos com um backup de segurança.

\section{Descrição e análise dos dados encontrados}

Os dados encontrados estão agrupados em três categorias, as quais obedecem à organização interna do roteiro semiestruturado de entrevista: I - Quem são nossos Guardiōes da Memória; II - A constituição (familiar e escolar) de nossos Guardióes; e III - O tesouro escondido - a cultura lúdica do período.

\section{I - Quem são nossos Guardiões da Memória}

Procurando conhecer a organização familiar dos entrevistados, esta pesquisa observou uma significativa diferença entre o número de integrantes nas famílias das quais os participantes são oriundos e o número de integrantes nas famílias que eles posteriormente vieram a formar. Os pesquisados, em sua maioria, procedem de famílias numerosas (com grande quantidade de irmãos). No entanto, quando constituem nova formação familiar, o número de filhos diminui significativamente comparado ao do núcleo familiar no qual tiveram origem (cf. Gráfico 1, a seguir). 
Gráfico 1 - Média comparativa do número de integrantes das famílias

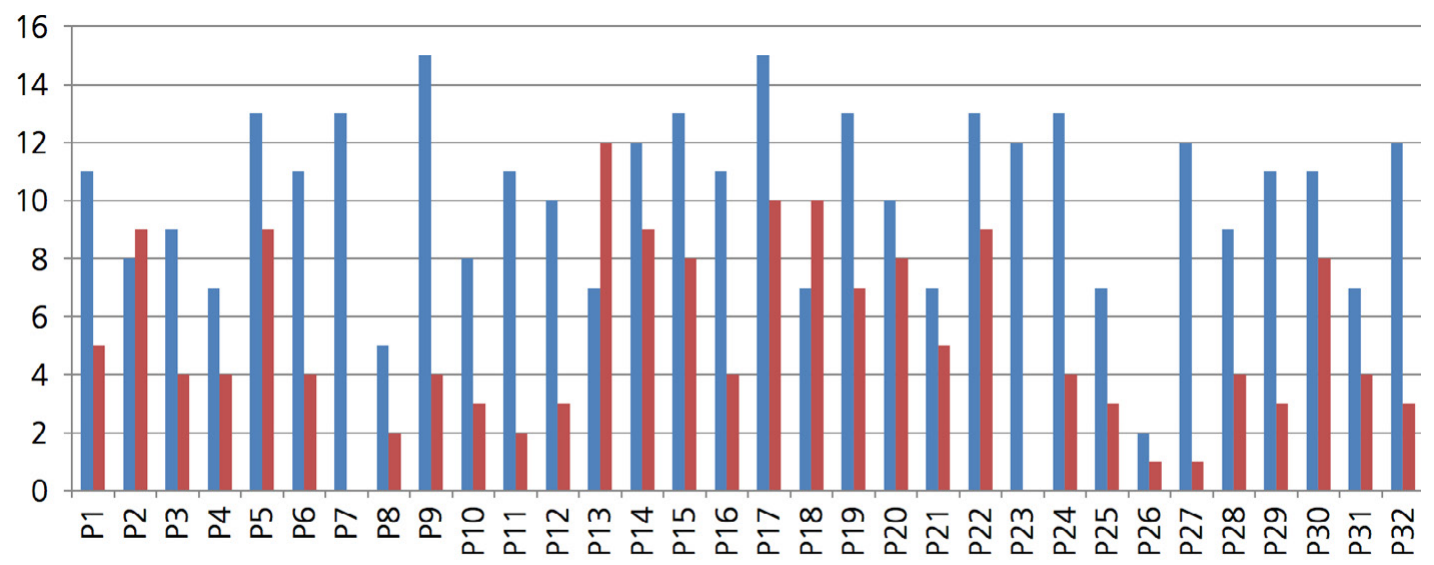

- Composicao Familiar de Origem

- Composicao Familiar Posterior

Fonte: Carneiro (2015).

Qual seria a relação ou o desdobramento desse dado para se pensar a constituição da cultura lúdica? Em nosso entendimento, há muitas variáveis que exercem influências sobre o ambiente do jogo e que podem ser determinantes para a existência e mesmo para algumas das diferentes manifestaçôes do fenômeno, dentre elas o espaço físico (geográfico), ou seja, o espaço livre disponível para brincar (com suas dimensóes e componentes), o espaço temporal (o tempo disponível e dedicado à brincadeira), a trajetória do indivíduo com suas experiências pessoais e familiares, seus recursos, suas motivaçóes, as pressóes e condiçóes sociais que o cercam, as atitudes dos pais diante do jogo.

Muitos fatores podem influenciar a forma como as crianças brincam. Para que haja o jogo, no sentido mais pleno do fenômeno, devem-se observar tanto os elementos extrínsecos como os intrínsecos. Esse equilíbrio seria o que Morais e Otta (2003, p. 127) denominam "zona lúdica". Emprestando o conceito das autoras, diríamos que zona lúdica seria o espaço no qual o jogo se manifesta e que concatena suas diferentes dimensóes (internas e externas): espaço físico, espaço temporal, trajetória e experiências do indivíduo, disponibilidade de objetos, disponibilidade de parceiros (irmãos e amigos, coetâneos ou não) com quem brincar, bem como a subjetividade, ou seja, as motivaçôes diante de pressôes e condiçóes sociais que configuram essa conjuntura, que é a zona lúdica. 
Desse modo, a diminuição de parceiros (irmãos), somada às abruptas transformaçóes arquitetônicas (espaço físico) e à escassez de objetos (recursos naturais ou matérias-primas), podem ter repercussōes consideráveis sobre determinadas expressóes do jogo, notadamente o jogo/folclore (tradicional), que, dada a não observância das particularidades de sua concretização, acaba sendo descaracterizado (CARNEIRO, 2017). Tais modificaçóes podem enfraquecer cenários em que a construção da infância pudesse se valer para ancorar seus substratos, bem como as manifestaçóes da dinâmica lúdica.

Buscando conhecer melhor nossos entrevistados (Guardiōes da Memória), também perguntamos a eles: "O que o senhor (a senhora) mais gosta de fazer (algo que lhe dê muita satisfação) em seu tempo livre?” Procuramos, assim, compreender quais são as atividades de lazer (aqui entendidas como passatempo), desenvolvidas atualmente, que lhes conferem alguma satisfação. Esse dado nos auxiliou no delineamento do perfil lúdico atual dos sujeitos da pesquisa e, de alguma forma, pôde indicar se eles guardam legados da experiência extraída da infância. Nesse levantamento encontramos seis núcleos principais de atividades mencionadas pelos pesquisados: atividades de natureza religiosa; jogos e atividades da cultura lúdica; atividades de natureza manual (confecção ou cultivo); práticas corporais (exercício físico); leitura; e interação midiática. Há, ainda, aqueles que disseram que não cultivam nenhuma atividade.

E, fechando a primeira categoria de análise, quisemos também saber se nossos entrevistados observavam mudanças na sociedade atual, quando comparada à da época em que viveram a infância. A questão foi assim formulada: "O senhor (a senhora) acredita que aconteceram muitas mudanças em nossa sociedade desde a época de sua infância até o presente momento? Poderia citar algumas de que se recorda?"

Todos os 32 foram unânimes e categóricos em afirmar que houve muitas mudanças. Com base nas respostas, reunimos 22 núcleos de elementos, fatos ou fenômenos em que os entrevistados observaram mudanças. Para melhor visualizarmos esses dados, apresentamos um gráfico a seguir. 
Gráfico 2 - A percepção quanto às mudanças

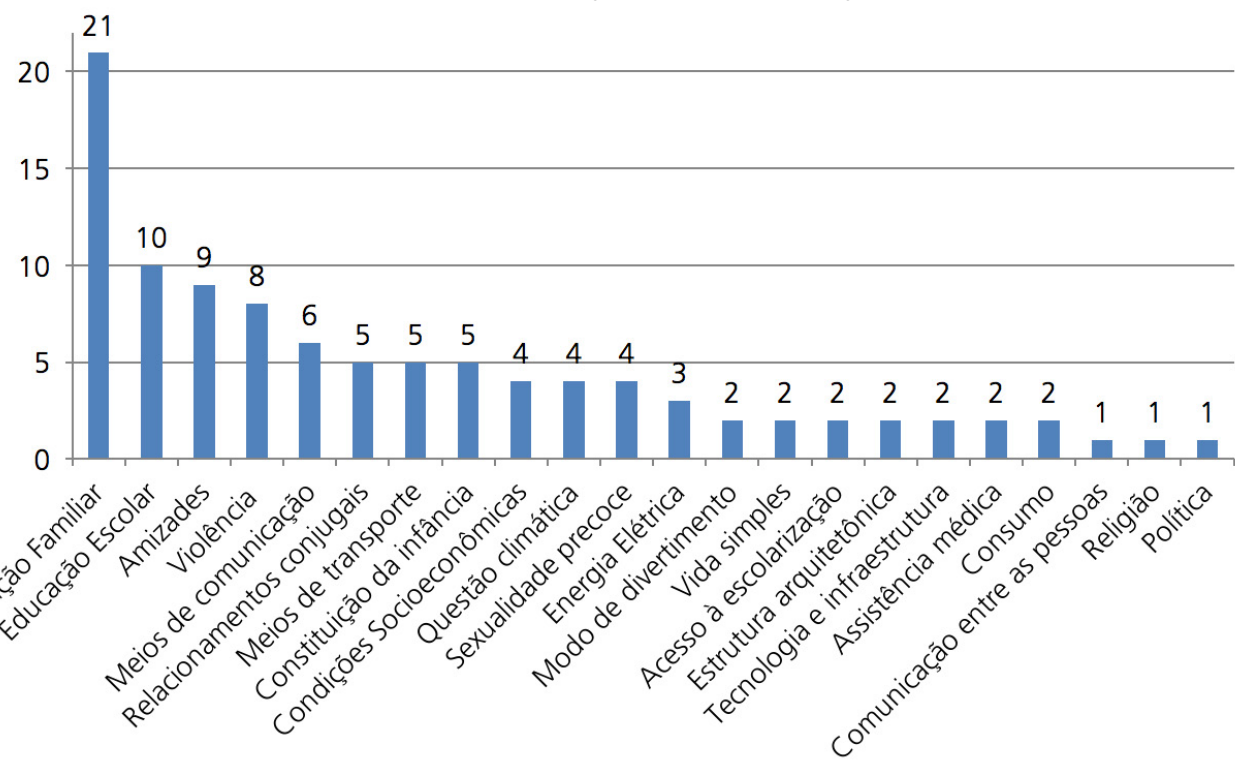

Fonte: Carneiro (2015).

Reunimos as respostas em quatro grupos, assim designados: natureza relacional, natureza tecnológica, fenômenos da natureza e natureza social. $\mathrm{O}$ núcleo natureza relacional (Educação Familiar [21]; Educação Escolar [10]; Amizades [9]; Comunicação [1]) soma um total de 41 mençôes e é, de longe, o cenário em que os entrevistados mais observam transformaçóes, em especial no que diz respeito à composição familiar, à formação fornecida por ela e aos diferentes vínculos afetivos que envolvem as relaçôes interpessoais.

De um modo geral, ao observarmos o conteúdo narrativo apresentado por nossos entrevistados, podemos dizer que a família, hoje, é vista, por eles com muita inquietação, sobretudo quando consideram as dificuldades na construção dos seus referenciais de autoridade, razão pela qual a família se torna, em sua opinião, frequentemente incapaz de cumprir as funções de cuidar, educar e socializar seus membros.

É necessário, logo, observar que a constituição dos laços depende de uma legitimação consistente das referências que deverão oferecer à criança as condiçóes para seu amadurecimento psíquico. Surgem aqui alguns problemas, assinalados por diferentes críticos da sociedade. Bauman (2004), preocupado com essas evidências, sugere que hoje os laços já nascem fragilizados, uma vez que se constroem em uma sociedade individualista na qual são privilegiadas as demandas de consumo de cada sujeito, isoladamente. 
O debate que aponta os impasses vividos nas transformaçóes dos laços contemporâneos é amplo, entretanto, é preciso levar em conta que tais transformações respondem às solicitaçóes inerentes à mutabilidade natural das diferentes redes de sociabilidades. Nessa direção, Lipovetsky (2007, p. 80) afirma que "A sociedade contemporânea é uma sociedade de desorganização psicológica que se reflete no processo de revigoramento subjetivo permanente, mediante uma pluralidade de 'propostas' que permitem reviver a esperança da felicidade." Assim, é preciso observar - sem prejulgamentos - em que medida essa flexibilidade e fluidez dos laços repercutem nos processos de subjetivação que têm origem na família, associando-as, ou não, às formas contemporâneas de sofrimentos psíquicos.

Os outros fatos ou fenômenos, citados por nossos entrevistados relativos às mudanças, poderiam ser abordados dentro de suas particularidades, todavia, dados os limites do presente texto, bem como a especificidade de nosso objeto de investigaçáa, vamos nos deter nos impactos (diretos ou indiretos) sobre a infância e a cultura lúdica, se ponderarmos que a cultura lúdica não emerge isolada da cultura geral, ou seja, elas estão intimamente ligadas à organizaçáo e aos conteúdos da infância. No entanto, alguns desses desdobramentos acabam repercutindo de maneira mais direta, como é caso da violência, do estímulo à sexualidade precoce, das condiçóes econômicas, do próprio estilo de vida, do exacerbado apelo ao consumo, entre outros.

Ao materializar o jogo por meio do brincar, a criança não apenas expressa e comunica suas experiências, mas as reelabora, reconhecendo-se como sujeito pertencente a um grupo social e a um contexto cultural que aprende sobre si mesmo e sobre os homens e suas relaçóes no mundo e também sobre os significados culturais do meio em que está inserido. Trata-se, portanto, de uma experiência de cultura, por meio da qual valores, habilidades, conhecimentos e formas de participação social são constituídos e reinventados pela açáo coletiva das crianças (CARNEIRO, 2015).

Desse modo, a oferta de espaço físico, a violência, os recursos (naturais ou não), o espaço temporal, a trajetória e as experiências do indivíduo, a disponibilidade de objetos, a disponibilidade de parceiros (consanguíneos ou não), as representaçóes sociais que ancoram as brincadeiras, bem como a subjetividade ou motivaçóes desse indivíduo diante das pressôes e condiçôes sociais afetam a cultura lúdica infantil.

Tal conjuntura pode, então, ser um indicativo ou revelar, ainda que parcialmente, a considerável diminuição de algumas expressóes e/ou manifestaçóes do jogo (notadamente o jogo/folclore) em decorrência do surgimento de outras. Assim, aqueles jogos tradicionalmente observados, que outrora eram realizados nas ruas e terrenos vazios (que faziam parte da cultura infantil), são menos encontrados: seja pela falta de espaço, devido ao processo de urbanizaçáo e industrializaçáo dos jogos, seja pela falta de segurança e aumento da violência, como apontam os estudos de Carneiro (2009, 2012, 2017). 
Embora observemos na cultura lúdica um caráter dinâmico, que acaba por incidir sobre ressignificaçôes e novas configuraçôes, entendemos que determinadas materializaçóes (e manifestações do jogo como categoria maior) guardam particularidades cuja não observância resultaria na impossibilidade de sua concretização, como é o caso do jogo/folclore (tradicional). Atividade antes prestigiada, vem perdendo espaço em decorrência das diferentes formas de furto da infância, do crescente aumento da violência e também de tantas outras questóes sociais que afetam o comportamento infantil.

Acentua-se, assim, a importância da preservação da cultura lúdica (jogo) enquanto patrimônio cultural, o que ocasionaria a própria preservação e evolução da memória social, que é "[...] o legado de um povo, ligada diretamente à constituição da identidade nacional e cultural desse povo." (UNESCO, 2007). A memória ocupa, desde bem cedo, um papel importante na construção da identidade da criança, além de simultaneamente assumir a sua missão de guardiã dos saberes infantis e das suas tradições culturais tâo bem refletidas nas festas (como rituais sagrados ou de cunho folclórico, que implicam a perpetuaçáo de uma herança cultural) e em diferentes revelaçóes do jogo. Esses âmbitos se misturam completamente nas suas vidas.

A cultura lúdica é, portanto, um patrimônio humano. Ou melhor, um legado que influencia o modo de ser e a identidade dos indivíduos (de maneira especial, do universo infantil) e grupos sociais, cujas tramas foram se tecendo historicamente e sendo transmitidas ao longo das diferentes sociedades. Passemos para a segunda categoria de análise dos dados.

\section{II - A constituição (familiar e escolar) de nossos Guardiões}

No intento de mapearmos as características e cenários da infância dos octogenários e nonagenários entrevistados, solicitamos que descrevessem o local de nascimento. De acordo com Bosi (1987, p. 356), "Há sempre uma casa privilegiada que podemos descrever bem, em geral a casa da infância ou [...] onde começou uma nova vida."

Dos 32 entrevistados, 26 desfrutaram de uma infância tipicamente rural, enquanto que 6 desfrutaram sua infância num ambiente mais urbano. Há uma forte predominância do ambiente campestre que envolveu a infância da maioria de nossos octogenários e nonagenários. Em dimensóes amplas ou macro, observamos um Brasil marcado por características agrícola e rural, cujo cenário foi um atrativo para imigrantes no começo do século, retirantes dos desdobramentos da Primeira Guerra Mundial e ansiosos por reconstruir a vida. 
As recordações da infância são caras para nossos anciãos, impregnadas de afetos. A casa materna é uma presença constante nas autobiografias (BOSI, 1987). E o interessante é que, por vezes, nem sempre é de fato a primeira casa que se conheceu, mas aquela cujas lembranças nos conduzem aos momentos mais importantes da infância.

A casa com a descrição das suas paisagens, dos seus cenários tão preciosos, revela estados de alma, como lembra Bachelard (1998), referindo-se às contribuiçóes dos psicólogos sobre a importância dos desenhos da casa feitos pelas crianças. "A casa e o universo não são simplesmente dois espaços justapostos." (p. 197). As lembranças das casas que habitamos, dos seus aposentos, numa revisita aos espaços oníricos da infância e da experiência humana, transportamnos para o contato conosco, com nossa própria intimidade: "aprendemos a morar em nós mesmos." (BACHELARD, 1998, p. 197).

Ainda nessa categoria, procuramos conhecer a realidade econômica da qual desfrutava o núcleo familiar de nossos entrevistados, quando eram crianças. A partir das respostas fornecidas, obtivemos: Condiçôes precárias e falta de elementos básicos (16\%); Condiçóes precárias sem a falta de elementos básicos (53\%); e Condições favoráveis com abundância (31\%).

Ao apreciarmos os elementos da realidade socioeconômica da família de nossos entrevistados, é preciso destacar que a infância é influenciada por fatores materiais e ideológicos da sociedade, bem como por valores hegemônicos estabelecidos em cada época, de modo que sobre ela atuam forças sociais, culturais, políticas e econômicas (CARNEIRO, 2015).

Em alguma medida, então, podemos inferir que cada agrupamento de sujeitos teria desfrutado de uma infância com elementos diferentes e, portanto, com características e sabores diferenciados.

Assim, tais condiçôes reverberam nas variáveis que exercem influências sobre o ambiente do jogo, podendo, inclusive, ser determinantes para algumas das diferentes manifestações do fenômeno ou da composição da vasta cultura lúdica. Ou seja, a trajetória do indivíduo, com suas experiências pessoais e familiares, seus recursos, suas motivações, as pressóes e condiçóes sociais que o cercam, as atitudes dos pais diante do jogo são variáveis importantes para o surgimento de determinadas expressóes ou manifestaçôes da cultura lúdica infantil.

Procuramos, por fim, nessa categoria, levantar informaçóes a respeito de como acontecia o acesso e de como era organizado o deslocamento para a escola. As respostas obtidas foram de três tipos: Todos Frequentaram; Alguns Frequentaram; Nenhum Frequentou a escola. É o que demonstra o gráfico a seguir: 
Gráfico 3 - Acesso à escola

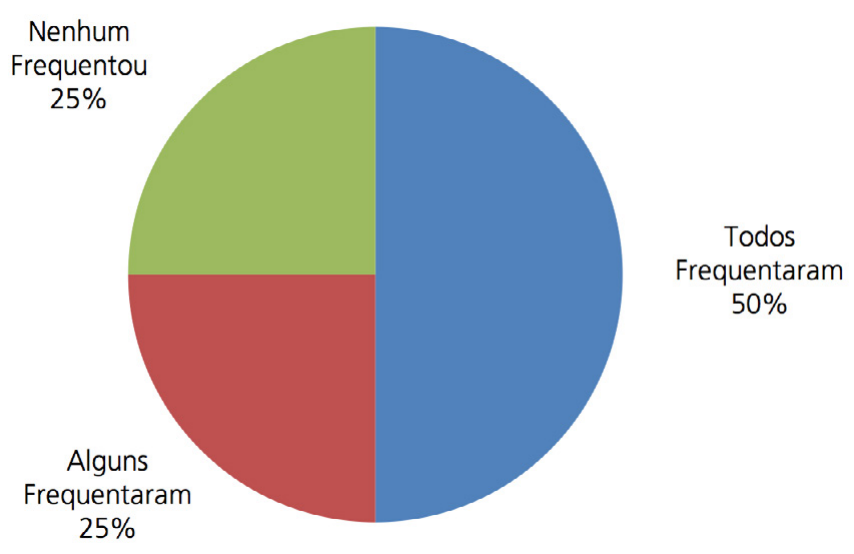

Fonte: Carneiro (2015).

Somando o agrupamento dos que nunca frequentaram a escola com aquele em que apenas parte dos integrantes da família frequentou, temos exatos $50 \%$ de alunos que, por diversas razóes, foram impossibilitados de participar do processo de escolarização. Em alguma medida, tal constatação corrobora o epíteto de a grande chaga nacional aplicado por alguns à educação brasileira do período (RODRIGUES, 1997), numa alusão à precariedade de oferta de espaços escolares que teve como produto o alarmante índice de $75 \%$ de analfabetismo na população brasileira em 1920 (GHIRALDELLI JR, 1991). Tal conjuntura engendrou reformas educacionais em âmbito nacional nas décadas de 20 e 30 , com o intuito de equacionar essa defasagem e adequar a escola e a educação ao contexto de modernidade pelo qual o país emergia.

\section{III - O tesouro escondido - a cultura lúdica do período}

Nossa última categoria de análise se propôs a descrever os principais componentes da cultura lúdica (manifestaçôes do jogo) vivenciada por nossos entrevistados.

Por que razão escolhemos denominar esse agrupamento de respostas como $o$ tesouro escondido? Trata-se de alusão nossa ao conteúdo de que se valia a cultura lúdica nas décadas de 20 e 30 . Julgamos que a compreensão desse momento histórico bem como seu arcabouço lúdico particular produzem o registro de práticas e vivências, objetivas e subjetivas, que estão escondidas e são trazidas à luz e à apreciação apenas quando prospectadas por meio de uma pesquisa, à semelhança da descoberta que faz um garimpeiro. 
O que estamos afirmando é a existência, em alguma medida, de um legado cultural, advindo das particularidades do jogo (cultura lúdica). E esse repertório cultural é dinâmico e mutável por ser transmitido e praticado por diversos grupos e civilizaçóes, sofrendo, em razão disso, inúmeras mudanças de contexto e forma, e sendo adaptado às necessidades de cada grupo e sociedade, sob a influência e característica de seu tempo e contexto. Como bem observou Friedmann (1996, n.p.), "[...] as brincadeiras são uma forma de descobrir o novo no antigo." E prossegue: "O jogo tradicional infantil é a produção espiritual do povo, acumulada através de um longo período de tempo. Esses jogos mudam no processo do esforço criativo coletivo e anônimo." (FRIEDMANN, 1996, p. 42).

Nesse movimento de mapearmos a cultura lúdica em busca das diferentes manifestaçôes do jogo, interpelamos nossos anciâos a respeito de como rememoravam sua infância, ou seja, qual era sua percepção sobre ela. Inicialmente, destacamos o quanto a infância é preciosa no ato de rememorar. $\mathrm{Na}$ forma de reordenar o tempo das lembranças, ela ocupa lugar de destaque, sempre aparece em larga escala, quase sem margens, como um chão que cede aos nossos pés e nos dá a sensação de que nossos passos se afundam. Como é difícil transpô-la e chegar à juventude! (BOSI, 1987).

Dos 32 entrevistados, 21 identificaram sua infância como sendo boa ou maravilhosa. Segundo as declaraçóes de nossos pesquisados, a infância guardava particularidades do período. Muitas variáveis podem ser observadas na composição da infância, bem como os aspectos da cultura lúdica (ambiente de jogo) por eles descritos, dentre os quais: o espaço arquitetônico, ou seja, o espaço livre e fartura de recursos naturais para brincar, o tempo disponível e dedicado à brincadeira, suas experiências interpessoais (amigos e familiares), as motivaçôes, dentre tantas outras.

Por sua vez, 7 participantes náo apresentaram juízo de valor a respeito da infância, deixando de classificá-la como ruim ou boa. Náo foi possível compreender as razóes dessa neutralidade. E, por fim, 4 participantes descreveram-na como uma experiência ruim.

Ainda, na mesma categoria, foi solicitado aos pesquisados que descrevessem as principais atividades (manifestaçóes da cultura lúdica) vivenciadas ao longo da infância. Ao passearmos pelos conteúdos da cultura lúdica descritos por nossos entrevistados, pudemos nos aperceber da riqueza formativa que tais experiências lhes proporcionaram. Esse dado ganha importância singular quando o examinamos à luz dos escritos de Brougère (1998), que mencionam o papel das experiências vividas, a aprendizagem paulatina e progressiva ao longo da infância, a agregação de elementos heterogêneos provenientes de fontes 
diversas, a interação grupal com toda a carga simbólica de aporte de novas e cada vez mais complexas competências, a interpretação e aplicaçáo das regras, a importância da criatividade, enfim, todas essas categorias numa panóplia de saberes e fazeres que se assumem como contributos decisivos para a competência do brincante perante o brinquedo e a sua vida cotidiana.

Como encontramos uma grande diversidade na composição das diferentes manifestaçóes da cultura lúdica, resolvemos apresentá-la, a seguir, em formato de gráfico, para, inclusive, identificar as que eram mais frequentes.

\section{Gráfico 4 - Brincadeiras mais frequentes}

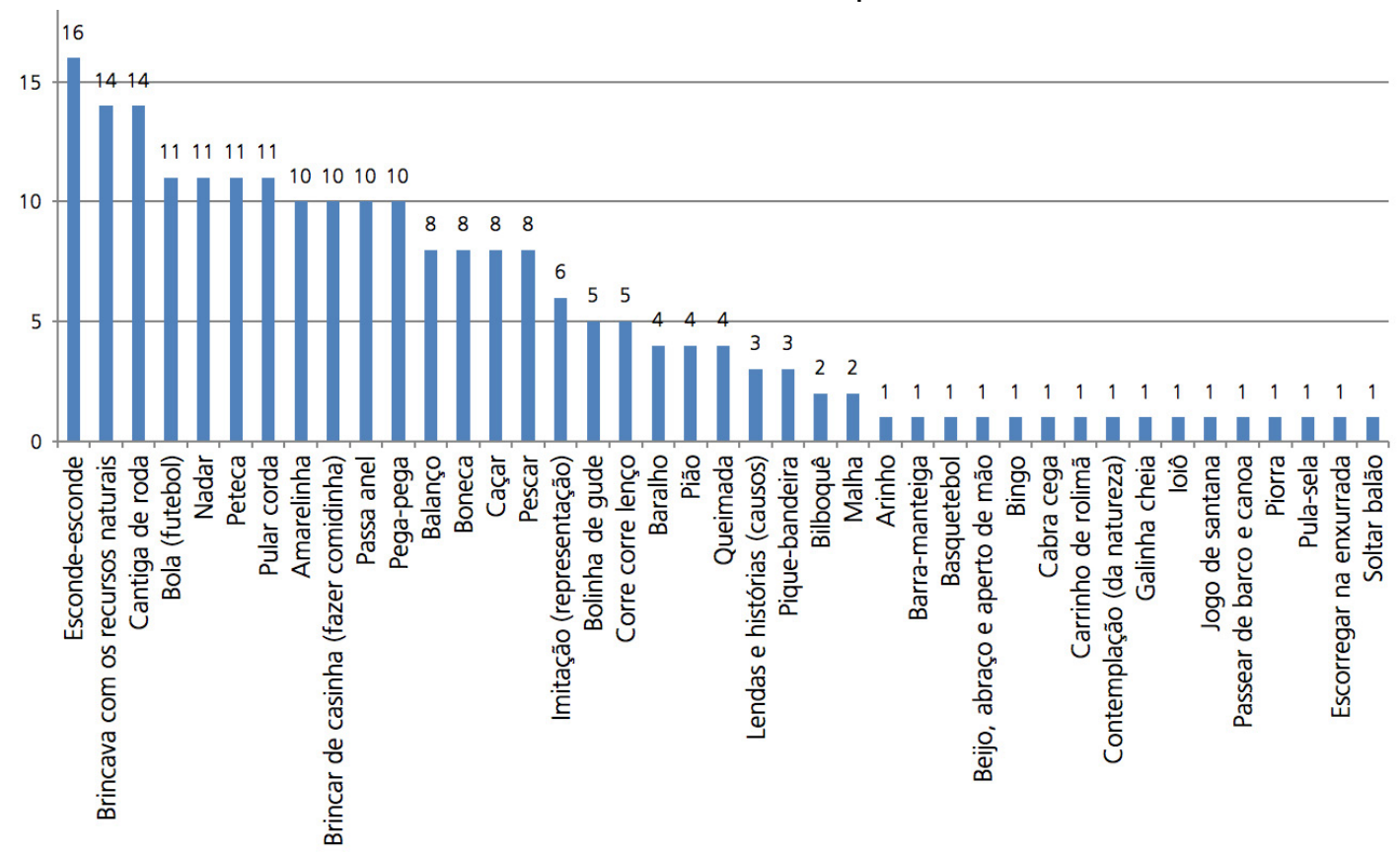

Fonte: Carneiro (2015).

Pode-se notar que as atividades lúdicas mais mencionadas dependiam exclusivamente dos recursos disponíveis na natureza, bem como revelam uma infância rural própria do momento histórico que o país atravessava. Observase, ainda, pouca ou nenhuma aquisição de materiais para sua concretização, um quadro reconhecidamente diferente daquele da configuração da infância nos dias atuais, em que as brincadeiras parecem estar inclinadas ou vinculadas à dependência do consumo.

Essa conjectura nos possibilita afirmar, com relativa segurança, que a cultura lúdica infantil é construída historicamente e se constitui como um legado cultural, 
um patrimônio da humanidade. E mais: empreendimentos que visem a preservála são importantíssimos, uma vez que as características da infância contemporânea se distanciam, e muito, daquelas observadas em outros tempos.

E, fechando a categoria, procuramos avançar no intento de recuperar os fragmentos desse tesouro perdido, numa espécie de arqueologia dessa cultura lúdica. Assim, interpelamos nossos pesquisados acerca dos brinquedos que faziam parte da infância. É interessante observar que a maioria dos brinquedos é produto de confecção própria. Os entrevistados usavam a criatividade e os recursos naturais disponíveis para construírem as brincadeiras ou os objetos que dessem suporte a elas. A aquisição de brinquedos industrializados, como o ioiô, descrito pelo (P 32), aparece nesse rol como uma exceção à artesania dessas crianças das décadas de 20 e 30.

O Gráfico 5 ajuda-nos a compreender que brinquedos eram mais frequentes nas brincadeiras de nossos entrevistados.

Gráfico 5 - Brinquedos mais frequentes

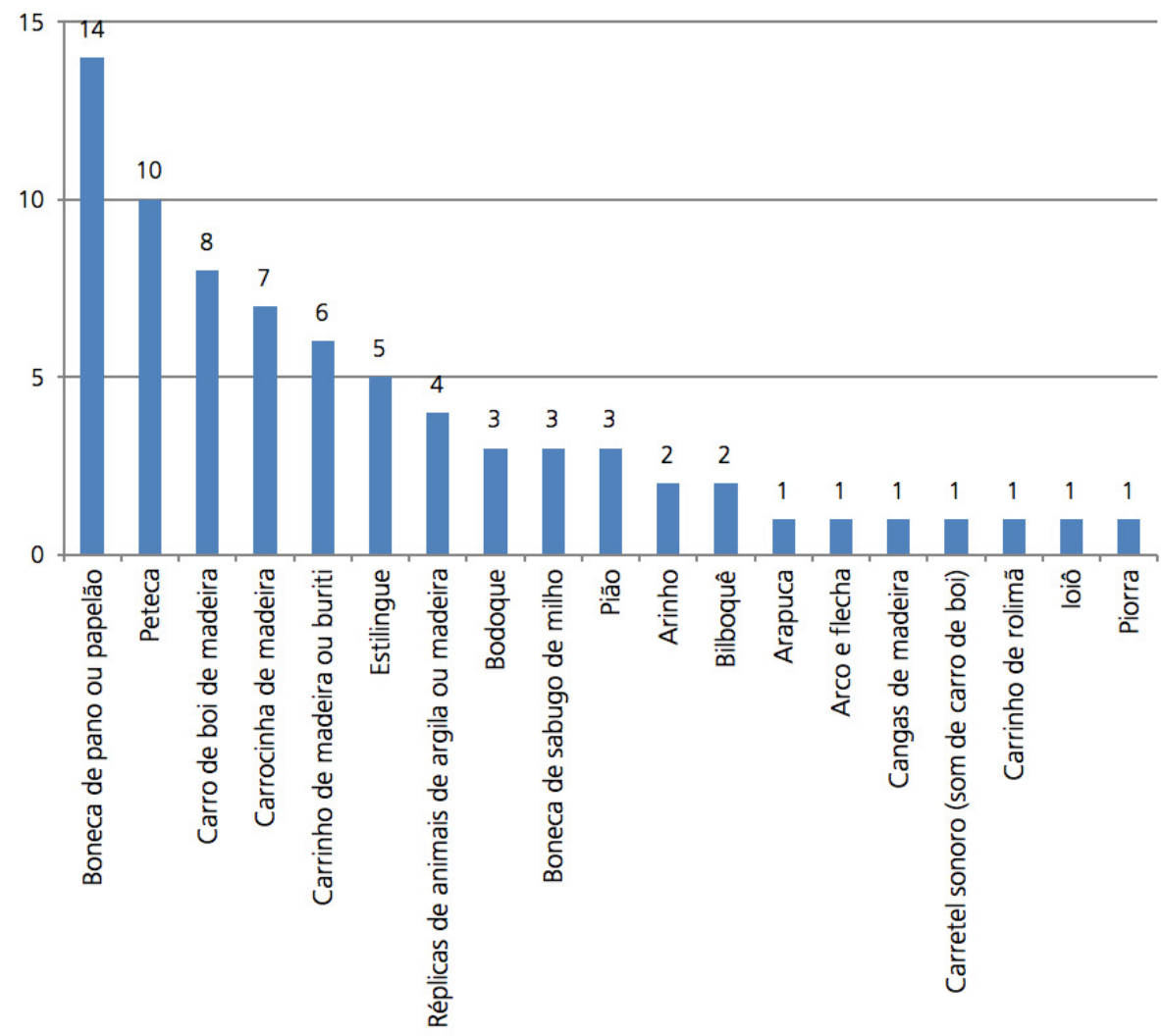

Fonte: Carneiro (2015). 
Primeiramente, estão dispostos os brinquedos que mais foram citados, seguidos daqueles que receberam poucas mençóes. Observemos que os primeiros estâo intrinsecamente ligados às condiçôes materiais e geográficas que permearam a infância do período, dada a sua relaçáo de dependência com os recursos naturais. Também se vinculam à forma e representação da infância para ancorar tais confecçôes ou justificar alguma aquisição. É o que afirma Brougère (1997, p. 52-53): "A cultura lúdica está imersa na cultura geral à qual a criança pertence. Ela retira elementos do repertório de imagens que representa a sociedade no seu conjunto; é preciso que se pense na importância da imitação na brincadeira."

Encontramos muitas informaçôes ao longo das entrevistas: algumas apresentadas de forma explícita, outras subentendidas nas narrativas de nossos Guardióes da Memória. Mesmo o comportamento dos participantes revelounos alguns dados, uma vez que "uma pesquisa é um compromisso afetivo, um trabalho ombro a ombro com o sujeito da pesquisa." (BOSI, 1987, p. 38). Ao vasculharmos a magnitude do ato de rememorar, concordamos com a autora: "a lembrança é como um diamante bruto que precisa ser lapidado pelo espírito". Todo nosso empenho ao longo deste estudo foi direcionado para extrair o mais lindo brilho das maravilhosas narrativas dos sujeitos entrevistados e assegurar a perpetuação de um conteúdo tão caro!

\section{Considerações finais}

$\mathrm{O}$ estudo em questão possibilitou que os 32 participantes da pesquisa percorressem os mapas afetivos de imagens e sons de sua infância rememorada e revivessem as experiências lúdicas. Sem dúvida, uma oportunidade de continuarem a se abastecer de significados que só a infância é capaz de fornecer.

À maneira de arqueólogos, empreendemos esforços no sentido de desencavar fragmentos de memória com os quais pudéssemos reconstituir uma época, não sem procurar consubstanciar dimensôes e sentidos que caracterizaram a infância daqueles que denominamos Guardióes da Memória, notadamente no que diz respeito às diferentes personificaçóes do jogo na composiçáo de suas vidas.

Ao conferir um registro ao vivido, resistindo, assim, ao aniquilamento da memória e à perda peremptória da cultura lúdica dos entrevistados, julgamos ter contribuído para amplificar e perenizar esse tesouro, verdadeiro patrimônio cultural do qual nossos sujeitos eram/são depositários.

Procurou-se, portanto, assegurar a essência de sua cultura, ponto de convergência, segundo Bosi (1987), onde o passado se conserva e o presente se prepara. A propósito, a aproximação entre as geraçóes contribui com a reflexão 
sobre a constituição da infância e das diferentes expressões lúdicas do século XXI, tarefa que, segundo Amado (2005), nenhum educador pode se esquivar. Nesse sentido, o diálogo é fundamental para superar o conflito intergeracional, pois permite tanto aprender com as novas expressóes lúdicas como conservar um legado historicamente construído, de maneira que uma e outra geração se beneficiem de todo o acervo da vasta cultura lúdica infantil. De acordo com Arendt (1992), a geração anterior pode servir de guia à atual, desde que seja capaz de nomear seus feitos e dar sentido a eles e, assim, poder ofertá-los àqueles que chegam ao mundo. $\mathrm{E}$ a estes, por sua vez, cabe a tarefa de ressignificar o legado recebido de acordo com sua maneira própria de ser e estar no mundo.

A transmissão da cultura constituída pelos inúmeros jogos tradicionais demanda vivências lúdicas que não se interiorizam senão por meio da convivência. Conviver, narrar e se fazer entender por símbolos que tenham equivalência são caminhos horizontais possíveis entre as diferentes trajetórias geracionais. É o que ocorre, por exemplo, quando um avô ensina um neto a construir e empinar uma pipa. Ao explicar como fez sua primeira pipa, está mantendo viva a memória. Essa não é uma tarefa fácil, mas necessária. Ainda mais quando se considera que o espaço da cultura lúdica confere à infância sua inserção no mundo adulto.

Ao materializar o jogo por meio do brincar, a criança não apenas expressa e comunica suas experiências, mas as reelabora. Ela se reconhece como sujeito pertencente a um grupo social e a um contexto cultural. Essa é, portanto, uma experiência de cultura, por meio da qual valores, habilidades, conhecimentos e formas de participação social são constituídos e reinventados pela ação coletiva das crianças. Muitas vezes, tal experiência só ocorre quando mediada por um adulto. Ou quando regrada pelo universo do mundo adulto, do qual a escola, por exemplo, é uma representação.

Desse modo, a experiência existencial do homem também se constrói no/ pelo jogo. A natureza imanente do jogo evoca transcendentalidade, convida ao rompimento com os interditos e os ditames que separam e distanciam as gerações. Como no convite de Benjamin (1994, p. 25), "eu viajo para conhecer minha geografia”, o jogo é uma jornada até as nossas raízes.

Nessa direção, a escola tem um papel fundamental, que é o de manter-se como favorecedora de experiências com as diferentes possibilidades do jogo. A cultura lúdica é muito vasta, e é preciso aprender as diferentes heranças que ela nos legou. Esse legado, que nos prepara para vivências futuras e experiências mundo afora, é um também abrigo para nossa subjetividade e nos situa como seres aprendentes. Por meio da cultura lúdica, aprendemos a compartilhar espaços, objetos, a abundância ou a escassez. Ela nos dá a chance de aprendermos e ensinarmos a velha e perene arte de ser feliz, atributo essencial do Homo ludens. 


\section{Referências}

ALBERTI, V. Manual da História Oral. São Paulo: Editora FGV, 2004.

AMADO, J. O universo dos brinquedos populares. Coimbra: Quarteto, 2005. ARENDT, H. Entre o passado e o futuro. Tradução Mauro W. Barbosa de Almeida. São Paulo: Perspectiva, 1992.

ARIÈS, P. História social da família e da criança. 2. ed. Rio de Janeiro: LTC, 1981. BACHELARD, G. A poética do espaço. Tradução de Antônio de Pádua Danesi. São Paulo: Martins Fontes, 1998.

BAUMAN, Z. Amor Líquido: sobre a fragilidade dos laços humanos. Rio de Janeiro: Jorge Zahar, 2004.

BECCHI, E. L'Antiquité. In: __ _ JULIA, Dominique (Org.) Historie de l'enfance en Occident. 1 Del'Antiquitéau XVII esiècle. Paris, Éditionsdu Seuil, mars. 1998. p. 43-73.

BENJAMIN, W. O narrador. In: BENJAMIN, W. (Ed.). Magia e técnica, arte e política: ensaios sobre literatura e história da cultura. 7. ed. São Paulo: Brasiliense, 1994, p.197-221.

BERGSON, H. Matéria e memória: ensaio sobre a relação do corpo com o espírito. Tradução de Paulo Neves. São Paulo: Martins Fontes, 1999.

BONI, V.; QUARESMA, S. J. Aprendendo a entrevistar: como fazer entrevista em Ciências Sociais. Em Tese - Revista Eletrônica dos Pós-Graduandos em Sociologia Política da UFSC. v. 2, n. 3, p. 68-80, jan./jul. 2005. Disponível em: < www.emtese.ufsc.br>. Acesso em: 31 maio 2014.

BOSI, E. Memória e sociedade: lembrança de velhos. São Paulo: T. A., 1987.

BRASIL. Ministério do Planejamento, Orçamento e Gestão. Instituto Brasileiro de Geografia e Estatística. Contagem Populacional. Disponível em: <http://www.ibge. gov.br/home/presidencia/noticias/29092003estatisticasecxx ...>. Acesso em: jul. 2012.

BROUGÈRE, G. Brinquedo e cultura. 2. ed. São Paulo: Cortez, 1997.

BROUGÈRE, G. O Jogo e a educaçáo. Porto Alegre: Artes Médicas, 1998.

BRUHNS, H. T. A dinâmica lúdica. 138 f. Dissertação (Mestrado em Filosofia da Educação)- Faculdade de Educação, Universidade Estadual de Campinas, Campinas, 1989. 
BRUHNS, H. T. O corpo parceiro e o corpo adversário. Campinas: Papirus, 1993. BUJES, M. I. E. Infância e poder: breves sugestôes para uma agenda de pesquisa. In: BUJES, M. I. E.; COSTA, M. V. Caminhos investigativos III: riscos e possibilidades de pesquisar nas fronteiras. Rio de Janeiro: DP\&A, 2005. p. 179-197.

BUYTENDIJK, U. F. J. J. O jogo humano. In: GADAMER, H. G.; VOGLER, P. Nova antropologia. São Paulo: EPU/Edusp, v. 4, 1974.

CAILLOIS, R. Os jogos e os homens: a máscara e a vertigem. Lisboa: Cotovia, 1990. CARNEIRO, K. T. O jogo na educaçáo física escolar: uma análise sobre as concepções atuais dos professores. 168 f. Dissertação (Mestrado em Educação Escolar) Faculdade de Ciências e Letras, Universidade Estadual Paulista, Araraquara, 2009.

CARNEIRO, K. T. O Jogo na Educação Física. São Paulo: Phorte Editora, 2012.

CARneIRO, K. T. Por uma memória do jogo: a presença do jogo na infância das décadas de 20 e 30. 2015. 273 f. Tese (Doutorado em Educação Escolar) - Faculdade de Ciências e Letras, Universidade Estadual Paulista, Araraquara, 2015.

CARNEIRO, K. T. Por uma memória do jogo: a presença do jogo na infância das décadas de 20 e 30. Curitiba: Appris Editora, 2017.

CHÂTEAU, J. O jogo e a criança. 2. ed. São Paulo: Summus, 1987.

CHIZZOTTI, A. A pesquisa qualitativa em ciências humanas e sociais: evolução e desafios Revista Portuguesa de Educaçáo, Braga, Portugal, Universidade do Minho, v. 16, n. 002, p. 221-236, 2003.

CONNERTON, P. Como as sociedades recordam. 2. ed. Tradução de M. M. Rocha. Oeiras: Celta, 1999.

DORNELLES, L. V. Infâncias que nos escapam: da criança na rua à criança cyber. Petrópolis: Vozes, 2005.

DUARTE JR., J. F. Fundamentos estéticos da educaçáo. 2. ed. Campinas: Papirus, 1988.

DUFLO, C. O jogo de Pascal a Schiller. Porto Alegre: Artmed, 1999.

EIGEN, M., WINCKER, R. O jogo: as leis naturais que regulam o acaso. Lisboa: Gradiva, 1989. 
ELKONIN, D. Psicologia do jogo. São Paulo: Martins Fontes, 1998.

FENTRESS, J.; WICKHAM, C. Memória Social: novas perspectivas sobre o passado. Lisboa: Editorial Teorema, 1992.

FERNANDES, F. Folclore e mudança social na cidade de Sáo Paulo. 2. ed. Petrópolis: Vozes, 1979.

FREIRE, J. B. Investigaçóes preliminares sobre o jogo. Tese (Livre docência), Campinas: FEF- UNICAMP, 2001.

FREIRE, J. B., SCAGLIA A. J. Educaçáo como prática corporal. São Paulo: Scipione, 2003.

FRIEDMANN, A. Brincar: crescer e aprender. O resgate do jogo infantil. São Paulo: Moderna, 1996.

GADAMER, H. G. Verdade e Método: traços fundamentais de uma hermenêutica filosófica. 4. ed. Petrópolis: Vozes, 2002.

GHIRALDELLI JR. P. Pedagogia e luta de classes (1935-37). São PauloIbitinga: Humanidades, 1991.

HALBWACHS, M. A memória coletiva. São Paulo: Vértice; Revista dos Tribunais, 1990.

HUIZINGA, J. Homo Ludens: o jogo como elemento da cultura. 4. ed. São Paulo: Perspectiva, 1999.

KISHIMOTO, T. M. O Jogo e a educação infantil. São Paulo: Pioneira, 2003. KISHIMOTO, T. M. (Org.) Jogo, brinquedo, brincadeira e a educaçáo. 9. ed. São Paulo: Cortez, 2006.

KUHLMANN JR, M.; FERNANDES, R. Sobre a história da infância. In: FARIA FILHO, L. M. (Org.). A infância e sua educaçáo. Materiais, práticas e representaçôes (Portugal e Brasil). Belo Horizonte: Autêntica, 2004.p.15-33.

LEBOVICI, S., DIATKINE, R. Significado e função do brinquedo na criança. Porto Alegre: Artes Médicas, 1988.

LEIF, J., BRUNELLE, L. O jogo pelo jogo. Rio de Janeiro: Zahar, 1978.

LIPOVETSKY, G. A sociedade da decepçáo. Barueri, SP: Manole, 2007.

LIRA, A. C. M. Problematizando o uso dos jogos e das brincadeiras na educaçáo das crianças de $\mathbf{0}$ a $\mathbf{6}$ anos: uma análise de propostas exemplares. 2009. 
175 f. Tese (Doutorado em Educação) - Faculdade de Educação, Universidade de São Paulo, São Paulo, 2009.

LOWENTHAL, D. Como conhecemos o passado. Tradução de L. Haddad. Projeto História, 17, p. 63-202, 1998.

MACEDO, L., PETTY, A. L. S., PASSOS, N. C. Aprender com jogos e situaçóes problemas. Porto Alegre: Artmed, 2000.

MARCELLINO, N. C. Lazer e educaçáo. Campinas: Papirus, 1987.

MARCELLINO, N. C. Lúdico: a busca da possibilidade ausente. In: MORAIS, R. (Org.). Filosofia, Educaçáo e sociedade. Campinas: Papirus, 1989. (Ensaios filosóficos).

MARTINELLI, M. L. Pesquisa Qualitativa: um instigante desafio. São Paulo: Editora Veras, 2003.

MATURANA, H., VERDEN-ZÖLlER, G. Amar e Brincar. São Paulo: Palas Athena, 2004.

MELLO, A. Psicomotricidade, Educaçáo Física e jogos infantis. 3. ed. São Paulo: Ibrasa, 1989.

MIRANDA, S. Do fascínio do jogo à alegria do aprender nas séries iniciais. Campinas: Papirus, 2001.

MORAIS, M. S.; OTTA, E. Entre a serra e o mar. In: CARVALHO, A. M. A.; MAGAlHÃES, C. M. C.; PONTES, F.A.R.; BICHARA, I. D. (Org.). Brincadeira e cultura: viajando pelo Brasil que brinca. São Paulo: Casa do Psicólogo, 2003. p. 127-156.

NARODOWSKI, Mariano. Infância e poder: a conformação da Pedagogia Moderna. Bragança Paulista: Editora da Universidade São Francisco, 2001.

NASAR, S. Uma mente brilhante. 2. ed. São Paulo: Record, 2002.

NEUMAN, J. V.; MORGENSTERN, O. Theory of games and economic behavior. Princeton, Princeton Univerty Press, 1990.

OLICK, J. K.; ROBBINS, J. Social Memory Studies: From "Collective Memory" to the Historical Sociology of Mnemonic Practices. Annual Review of Sociology, v. 24, p. 105-140, aug. 1998.

ORGANIZAÇÃO DAS NAÇÓES UNIDAS PARA A EDUCAÇÃO, A CIÊNCIA E A CULTURA (2007). Disponível em: <http://www.unesco.org. br/>. Acesso em: 5 jan. 2007. 
PAES, R. R. Aprendizagem e competiçáo precoce: o caso do basquetebol. Campinas: Editora da Unicamp, 1992.

PASCAL, B. Pensamentos. São Paulo: Martin Claret, 2003.

PIAGET, J. O juízo moral na criança. 2. ed. São Paulo: Summus, 1932/1994.

POSTMAN, N. O Desaparecimento da Infância. Tradução de Suzana Menescal de A. Carvalho e José Laurenio de Melo. Rio de Janeiro: Grafhia Editorial, 1999.

RETONDAR, J. J. M. Teoria do jogo: a dimensão lúdica da existência humana. Petrópolis: Vozes, 2007.

RODRIGUES, M. O Brasil na década de 1920: os anos que mudaram tudo. São Paulo: Ática, 1997.

ROSAMILHA, N. Psicologia do jogo e aprendizagem infantil. São Paulo: Pioneira, 1979.

ROUSSEAU, J. J. Emílio ou Da educação. Rio de Janeiro: Bertrand Brasil, 1974.

SANTOS, M. S. dos. O pesadelo da amnésia coletiva: um estudo sobre os conceitos de memória, tradição e traços do passado. Cadernos de Sociomuseologia, Lisboa, Centros de Estudos de Sociomuseologia/Universidade Lusófona de Humanidades e Tecnologias, n. 19, p. 139-171, 2002, Disponível em: <http://revistas.ulusofona.pt/ index.php/cadernosociomuseologia/article/view/370/279>. Acesso em: 08 set. 2011.

SCAGLIA, J. A. O futebol e os jogos/brincadeiras de bola com os pés: todos semelhantes, todos diferentes. 2003. 164 f. Tese (Doutorado em Pedagogia do Movimento) Faculdade de Educação Física, Universidade de Campinas, Campinas, 2003.

SCAGLIA, J. A.; CARNEIRO, K. T.; CAMARGO, R. L. O Jogo/Brincadeira como elemento pedagógico no sistema prisional. Cáceres: Editora UNEMAT, 2014.

SCHILLER, F. A Educação estética do homem. 4. ed. São Paulo: Iluminuras, 2002.

STEINBERG, Shirley R.; KINCHELOE, Joe L. Sem segredos: cultura infantil, saturação de informação e infância pós-moderna. In: . Cultura infantil: a construção corporativa da infância. Rio de Janeiro: Civilização Brasileira, 2001. p. 9-52.

VEIGA, C. G. Infância e modernidade: ações, saberes e sujeitos. In: FARIA FILHO, Luciano Mendes (Org.). A infância e sua educação: materiais, práticas e representaçóes. Belo Horizonte: Autêntica, 2004. p. 35-82. 
VYGOTSKY, L. S. A formaçáo social da mente. 6. ed. São Paulo: Martins Fontes, 2000.

WINNICOTT, D. W. O brincar \& a realidade. Rio de Janeiro: Imago, 1975.

WITTGENSTEIN, L. Investigaçóes filosóficas. São Paulo: Nova Cultural, 1999. 